\title{
Patrón sugestivo de anticuerpos contra el aparato de Golgi en un paciente con uveitis
}

\author{
Sugestive pattern of anti-Golgi complex antibodies in a patient with uveitis
}

\author{
Kevin Ortiz, Egly Álvarez, Ricardo Arreola, Maynor Herrera* \\ Unidad de Reumatología, Hospital Roosevelt, Guatemala
}

*Autor al que se dirige la correspondencia: drherreram@gmail.com

Recibido: 18 de febrero 2018 / Revisión: 20 de febrero 2019 / Aceptado: 28 de marzo 2019

\section{Resumen}

T os anticuerpos dirigidos contra el aparato de Golgi fueron inicialmente descritos en un paciente con Síndrome ¿de Sjögren en 1982. Estos anticuerpos forman parte de los anticuerpos antinucleares y producen un patrón característico en las células Hep-2. Desde su descubrimiento no se ha logrado establecer ninguna asociación clara con alguna enfermedad autoinmune y/o manifestación clínica. En el presente artículo se reporta el primer caso de anticuerpos antinucleares por fluorescencia (Fana) positivo con un patrón polar/sugestivo de anti-Golgi en Guatemala encontrado en el Laboratorio de Inmunología-Autoinmunidad del Hospital Roosevelt en un paciente masculino con una uveítis en el ojo derecho y que presentó pruebas de laboratorio positivas para toxoplasma, rubeola IgG, citomegalovirus, y herpes 1 y 2 . Este patrón ha sido encontrado en personas con diferentes enfermedades autoinmunes pero no se ha logrado establecer asociación con alguna enfermedad en particular.

Palabras claves: Autoinmunidad, anticuerpos antinucleares, inmunofluorescencia, inmunología

\begin{abstract}
$\mathrm{T}$

The anti-Golgi complex antibodies were first described in a patient with Sjögren Syndrome in 1982. These antibodies are part of the antinuclear antibodies and they have a characteristic staining pattern in Hep-2 cells. They have not been associated with any autoimmune disease and/or clinical manifestation. In the present case we report the first nuclear antibodies (ANA) with a staining pattern polar/anti-Golgi-like founded in the Immunology-Autoimmunity Laboratory at Roosevelt Hospital in a male patient with an uveitis on the right eye and positive IgG serology for toxoplasma, rubella, cytomegalovirus and herpes 1 and 2 . This pattern has been founded in patients with different autoimmune diseases, but they haven't been associated with a disease.
\end{abstract}

Keywords: autoimmunity, antinuclear antibodies, immunofluorescence, immunology 


\section{Introducción}

Los anticuerpos antinucleares (ANA) son marcadores serológicos característicos de varias enfermedades reumatológicas autoinmunes (como el lupus eritematoso sistémico [LES], síndrome de Sjögren [SS], enfermedad mixta del tejido conectivo [EMTC] y la esclerosis sistémica [ESc]). Recientemente se recomendó cambiar el término ANA por anticuerpos dirigidos contra componentes celulares debido a que los anticuerpos no se encuentran únicamente dirigidos contra antígenos localizados en el núcleo (Agmon-Levin et al., 2014). La última clasificación de los patrones observados en los ANA incluye nueve citoplasmáticos (AC-15 a AC23 ); incluido en estos patrones se encuentra el AC-22 o patrón polar/parecido a Golgi. La descripción oficial de este patrón lo describe como gránulos gruesos o láminas en un lado de la célula dispersas en la periferia del núcleo que corresponden a los sáculos del aparato de Golgi en células Hep-2 (Chan et al., 2015).

El aparato de Golgi es una organela citoplasmática localizada en la periferia del núcleo de las células eucariotas y se caracteriza por estar formado por unos 80 dictiosomas y estos a su vez estar compuestos por 40 o 60 sáculos aplanados y rodeados de membrana que se encuentran apilados unos encima de otros y que funcionalmente se puede dividir en tres regiones (cis-, medial- y trans Golgi). Esta organela fue inicialmente reportada por Santiago Ramon y Cajal en 1897 y luego fue descrita en gran detalle por Camilo Golgi. Dentro de sus funciones se encuentra la glicosilación de proteínas, selección, destinación y glicosilación de lípidos, almacenamiento y distribución de lisosomas y peroxisomas, y síntesis de polisacáridos de la matriz extracelular (Nozawa, Fritzler, \& Chan, 2005).

Los anticuerpos dirigidos contra el aparato de Golgi (anti-Golgi) fueron inicialmente descritos en un paciente con SS y linfoma como una tinción moteada citoplasmática que rodeaba parcialmente el núcleo de las células de disecciones de hígado de rata (Rodríguez, Gelpi, Thomson, Real, \& Fernández, 1982). Posterior a esta descripción se encontró la presencia de este anticuerpo también en sueros de pacientes con LES, artritis reumatoide (AR), hepatitis autoinmune (Fritzler, Etherington, Sokoluk, Valencia, \& Kinsella, 1984; Wallis, Greing, Dunphy, Owen, \& McHugh, 2012), miositis y enfermedad pulmonar intersticial (Andrejevic, Milenkovic, \& Stojsic, 2015).

La caracterización de los antígenos contra los cuales se encuentran dirigidos los anti-Golgi por in- munoprecipitación e inmunoblot demostró que las proteínas reconocidas por estos anticuerpos son heterogéneas y de pesos moleculares que van desde 35 hasta 260 kDa (Kooy, Toh, \& Gleenson, 1994). Caracterizaciones posteriores demostraron que la mayor parte de los anti-Golgi se dirigen contra las proteínas giantina/ macrogolgina/Precursor de glicoproteína 372, golgina-245/p230, Proteína asociada a los microtubulos de Golgi-210, golgina-160/Precursor de glicoproteína 170, golgina-95/GM130 y golgina-97. Inicialmente las golginas fueron descritas como autoantígenos del aparato de Golgi reconocidos por anticuerpos de pacientes con enfermedades autoinmunes (Fritzler, Hamel, Ochs, \& Chan, 1993). Las golginas poseen una masa molecular relativamente alta (100-370 kDa) y comparten características estructurales que incluyen motivos de hélices superenrolladas de hélices alfa a través de toda la proteína con excepción de los amino y carboxilo terminales de la proteína (Nozawa, Fritzler, von Mülen, \& Chan, 2004). Algunas proteínas del aparato de Golgi, como la golgina-84 han sido clasificadas como golginas debido a que poseen motivos de superhélice, aunque estas no hayan sido identificadas como autoantígenos (Nozawa et al., 2005). De particular interés es la giantina la cual ha demostrado ser de importancia en la reparación del aparato de Golgi después de recibir dosis elevadas de alcohol (Casey, Thomes, Manca, \& Petrosyan, 2018).

Otra característica compartida entre los autoantígenos del aparato de Golgi, dado por la evidencia bioquímica y la microscopía electrónica, es que estos son proteínas periféricas o transmembrana localizados en la porción citoplasmática del aparato de Golgi. Esto ha llevado a proponer a algunos investigadores que los autoantígenos del aparato de Golgi poseen características bioquímicas y funcionales en común que los hacen propensos a ser objetivos autoimunes dentro de las más de 100 proteínas del aparato de Golgi descritos a la fecha (Nozawa et al., 2005). La utilidad de los anti-Golgi en el diagnóstico de las enfermedades autoinmunes aún se encuentra en estudio, principalmente por su baja frecuencia y que también han sido encontrados en personas sin la presencia de una enfermedad autoinmune (DíAmico, Zazzetti, Schiel, Barreira, \& Babini, 2012).

En el presente trabajo se realiza la primera descripción conocida a la fecha de un paciente guatemalteco que presenta anticuerpos anti-Golgi detectado en células Hep-2000. El suero del paciente fue analizado como parte del proyecto de la Dirección General de Investigación (Digi) "Determinación de la dilución óptima de anticuerpos antinucleares por inmunofluo- 
rescencia para el diagnóstico de enfermedades reumatológicas autoinmunes".

\section{Presentación del caso}

Paciente masculino de 46 años de edad quien refirió que hace tres años inició con irritación en ambos ojos y con disminución de la agudeza visual y lagrimeo en el ojo derecho desde hacía un año, por lo que consultó a la Unidad Nacional de Oftalmología quienes indicaron que cursa con uveítis y lo refieren a la Unidad de Reumatología para evaluación. El paciente refiere consumo de tabaco desde hace 20 años y alergia a la penicilina. Las pruebas de laboratorio fueron positivas para toxoplasma $\operatorname{IgG}(540 \mathrm{UI} / \mathrm{mL}$ [VR 0-8 UI/mL]), rubeola IgG $(16 \mathrm{UI} / \mathrm{m}$ [VR 0-5 UI/mL]), citomegalovirus IgG (10.3 [Positi- vo>1.1]), y herpes 1 y $2 \operatorname{IgG}(43.1$ [Positivo>1.1]), hemoglobina $17.5 \mathrm{~g} / \mathrm{dL}$, globulos rojos $5.45 \mathrm{M} / \mathrm{uL}$, hematocrito $49.3 \%$ y globulos blancos $8.18 \mathrm{~GB} / \mathrm{uL}$, factor reumatoide $5.6 \mathrm{U} / \mathrm{mL}$, proteína $\mathrm{C}$ reactiva 5.5 $\mathrm{mg} / \mathrm{dL}$, glucosa $92.9 \mathrm{mg} / \mathrm{dL}$, creatinina $0.71 \mathrm{mg} / \mathrm{dL}$, nitrógeno de urea $10.9 \mathrm{mg} / \mathrm{dL}$. La evaluación por parte del médico oftalmólogo del Hospital Roosevelt indica que el paciente presenta uveítis anterior en ojo derecho. Debido a la presencia de uveítis se le solicita al paciente la realización de pruebas al Laboratorio de Inmunología-Autoinmunidad en donde se le realiza ANA por inmunofluorescencia (Fana) los cuales dan positivo con un patrón sugestivo de anti-Golgi desde una dilución $1 / 80$ hasta $1 / 320$ (Figura 1 ) y anticuerpos contra el citoplasma del neutrófilo (Ancas) los cuales son negativos por Elisa e inmunofluorescencia. La

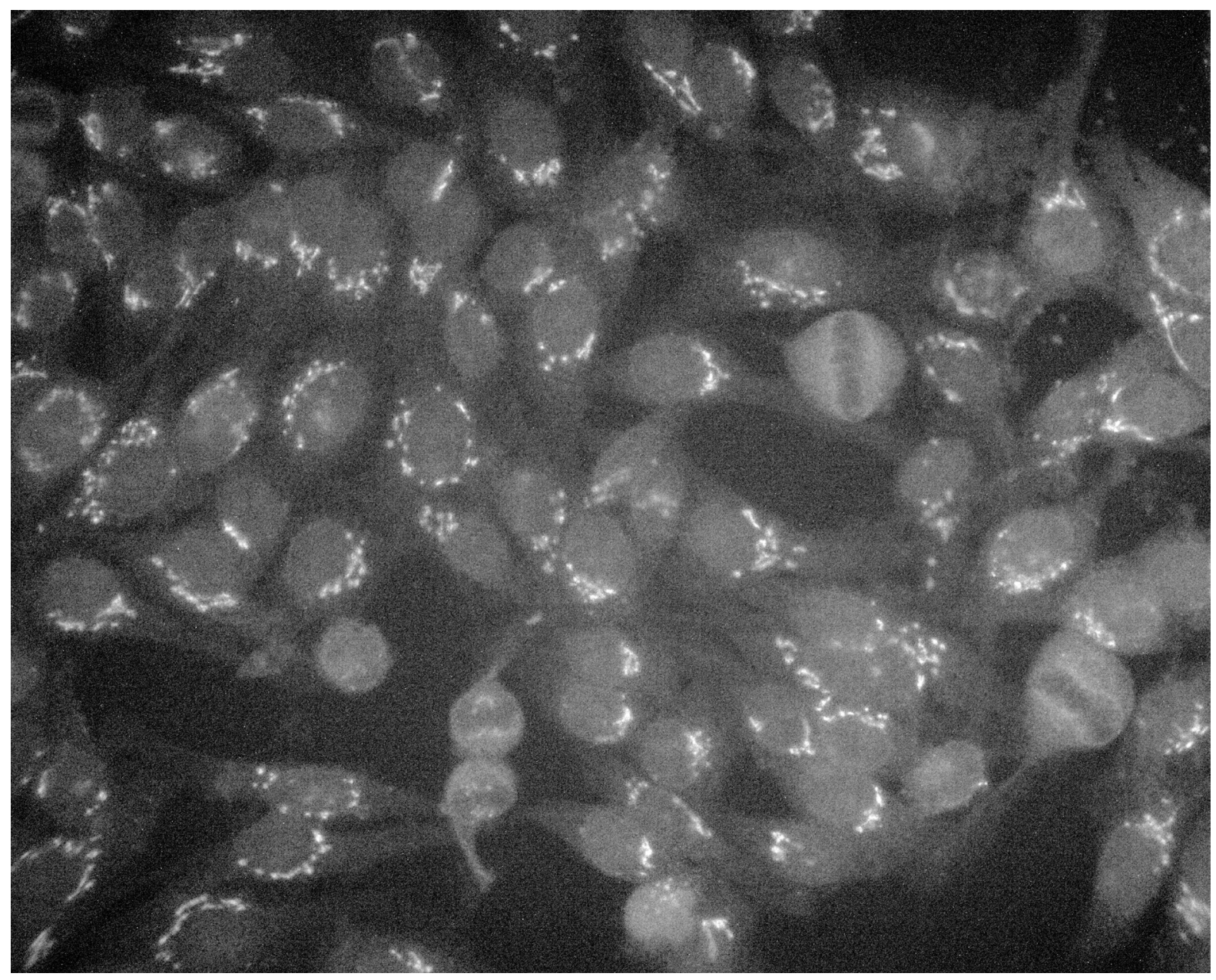

Figura 1. Patrón polar/sugestivo de anti-Golgi o AC-22 en células Hep-2000 con una dilución 1/80. 
evaluación por el médico reumatólogo posterior a la realización de las pruebas no evidencia presencia de enfermedad autoinmune, por lo que se refiere al paciente para su seguimiento en la unidad de oftalmología y se le vuelve a citar a los seis meses para seguimiento.

\section{Discusión}

La información sobre la prevalencia de los anticuerpos anti-Golgi es muy variada, aunque los estudios más recientes llevados a cabo en células Hep-2 han identificado una prevalencia baja (Hong et al., 2004; Vermeersch, Van Den Bergh, Blockmans, Westhovens, \& Bossuyt, 2011). En un estudio llevado a cabo en el Hospital Universitario de Leuven en Bélgica se revisó los resultados de 51,586 personas referidas al laboratorio en un período de 10 años para la realización de un Fana, de estos pacientes solamente se detectaron 20 casos en los que se presentó el patrón anti-Golgi, lo cual representa una frecuencia del $0.11 \%$. A estos pacientes se les realizó un seguimiento promedio de 9 meses y solamente se detectó un nuevo caso diagnosticado de síndrome de Sjögren (Vermeersch et al., 2011).

Estos resultados son bastante similares a los obtenidos en un estudio llevado a cabo en el Hospital Chang Gung de Taiwan, en donde se evaluaron los sueros 5,983 pacientes referidos al laboratorio para la realización de un Fana. En este estudio se encontraron 12 pacientes que presentaron el patrón anti-Golgi utilizando células Hep-2. De esos 12 pacientes dos fueron diagnosticados con LES y dos con AR (Hong et al., 2004). En Latinoamérica se realizó la descripción de tres casos en Argentina, dos de los casos presentaron síntomas de Sicca y uno era un paciente con LES (D'Amico et al., 2012).

Como puede observarse en ambos estudios la presencia de anti-Golgi parece no encontrarse asociada a la presentación de una enfermedad reumatológica autoinmune en los pacientes que presentan este patrón. Una observación interesante fue realizada por Vermeersch y colaboradores (2011) quienes indican que el único caso de SS que presentó este patrón tuvo títulos elevados de anti-Golgi. Esta misma observación ya había sido planteada con anterioridad en un estudio llevado a cabo en la Universidad de Padua, Italia. En el estudio se presentan dos casos en los cuales se detectaron anti-Golgi a una dilución de 1/5120 y se llegó al diagnóstico de una enfermedad autoinmune (Bizzaro, Pasini, Ghirardello, \& Finco, 1999). Esta misma observación puede realizarse del estudio presentado por
Fritzler y colaboradores (1984) en el que se presentan ocho casos de pacientes con anti-Golgi. En esa ocasión seis de los casos presentados fueron diagnosticados con LES y todos presentaron títulos de anti-Golgi mayores o iguales a $1 / 640$, los otros dos casos restantes fueron una esclerosis sistémica (anti-Golgi a una dilución 1/80) y una hepatitis (anti-Golgi a una dilución 1/320).

En un estudio realizado por Wallis y colaboradores (2012) en donde revisaron los Fana de 9,841 pacientes de un hospital especializado en enfermedades reumatológicas en búsqueda de anti-Golgi se observó la presencia de estos anticuerpos cuando los pacientes presentaban una alta actividad de la enfermedad y que estos desaparecían al estar los pacientes en remisión. Esta misma observación fue realizada en estudios anteriores (Bizzaro et al., 1999; Vermeersch et al., 2011). Por lo que la presencia de estos anticuerpos podría no estar relacionada de forma directa a una enfermedad sino ser más bien un indicador de la actividad de la enfermedad, sin embargo es necesario una mayor cantidad de estudios que puedan comprobar esta teoría.

El paciente del presente caso presentó anticuerpos antinucleares positivos mediante inmunofluorescencia en células Hep-2000 con presencia del patrón anti-Golgi (Figura 1); el suero del paciente mantuvo el resultado positivo desde una dilución 1/80 hasta una dilución $1 / 320$ y como se mencionó con anterioridad al momento de la realización de la presentación del caso aún no se había establecido un diagnóstico para el paciente. Un dato interesante es la presencia de uveítis en el paciente. A la fecha no se conoce de ningún caso de pacientes que cursen con esta manifestación clínica, por lo que la presentación del caso sería la primera descripción de un paciente con uveítis y un Fana positivo con un patrón anti-Golgi.

Otra observación interesante es la positividad de los anticuerpos contra agentes infecciosos. Un estudio llevado a cabo en Brest, Francia demostró en pacientes que presentaron anticuerpos contra citomegalovirus y rubeola la presencia de anti-Golgi hasta en un $28.6 \%$ de los pacientes analizados. Esta prevalencia es bastante elevada si se compara con la reportada por otros autores, sin embargo es importante mencionar que la línea celular empleada para la detección de los Fana en ese estudio fue la IMR-33 y los anticuerpos fueron analizados empleando una dilución 1/40 (Blaschek et al., 1988).

En conclusión, el presente caso es el primer reporte de un anti-Golgi detectado mediante inmunofluorencencia en Guatemala y el primer caso asociado a uveítis reportado en la literatura. 


\section{Referencias}

Agmon-Levin, N., Damoiseaux, J., Kallenberg, C., Sack, U., Witte, T., Herold, M., É Shoenfeld, Y. (2014). International recommendations for the assessment of autoantibodies to cellular antigens referred to as anti-nuclear antibodies. Annals of the Rheumatic Diseases, 73(1), 17-23. doi:10.1136/ annrheumdis-2013-203863

Andrejevic, S., Milenkovic, B., \& Stojsic, J. (2015). Coexistence of autoantibodies against the Golgi complex and Ro52 antigen in a patient with nonspecific interstitial pneumonia. Internal Medicine, 55, 273-278. doi:10.2169/internalmedicine.55.3832

Bizzaro, N., Pasini, P., Ghirardello, A., \& Finco, B. (1999). High anti-Golgi autoantibody levels: An early sign of autoimmune disease? Clinical Rheumatology, 18(4), 346-348. doi:10.1007/ s100670050115

Blaschek, M. A., Pennec, Y. L., Simitzis, A. M., Goff, P. L. E., Lamour, A., Kerdraon, G., É Youinou, P. (1988). Anti-Golgi complex autoantibodies in patients with primary Sjögren's Syndrome. Scandinavian Journal of Immunology, 17, 291-296.

Casey, C. A., Thomes, P., Manca, S., \& Petrosyan. (2018). Giantin is required for post-alcohol recovery of Golgi in liver cells. Biomolecules, 8 , 150-164. doi:10.3390/biom8040150

Chan, E. K. L., Damoiseaux, J., Carballo, O. G., Conrad, K., de Melo Cruvinel, W., Francescantonio, P. L. C., É Andrade, L. E. C. (2015). Report of the first international consensus on standardized nomenclature of antinuclear antibody HEp-2 cell patterns (ICAP) 2014-2015. Frontiers in Immunology, 6, 1-13. doi:10.3389/fimmu.2015.00412

D'Amico, M. A., Zazzetti, F., Schiel, A., Barreira, J. C., \& Babini, A. M. (2012). Anticuerpos anti-Golgi en las enfermedades del tejido conectivo. Revista Argentina de Reumatología, 23(1), 24-28.

Fritzler, M. J., Etherington, J., Sokoluk, C., Valenciaf, D. W., \& Kinsella, T. D. (1984). Antibodies from patients with autoimmune disease react with a cytoplasmic antigen in the Golgi apparatus. The Journal of Immunology, 132(6), 2904-2908.
Fritzler, M. J., Hamel, J. C., Ochs, R. L., \& Chan, E. K. L. (1993). Molecular characterization of two human autoantigens: Unique cDNAs encoding 95- and $160-\mathrm{kD}$ proteins of a putative family in the Golgi complex. Journal of Experimental Medicine, 178, 49-62. doi:10.1084/jem.178.1.49

Hong, H. S., Chung, W. H., Hung, S. I., Chen, M. J., Lee, S. H., \& Yang, L. C. (2004). Clinical association of anti-Golgi autoantibodies and their autoantigens. Scandinavian Journal of Immunology, 59(1), 79-87. doi:10.1111/j.03009475.2004.01353.x

Kooy, J., Toh, B.-H., \& Gleenson, P. A. (1994). Heterogeneity of human anti-Golgi auto-antibodies: Reactivity with components from 35 to $260 \mathrm{kDa}$. Immunology and Cell Biology, 72(2), 123-127. doi:10.1111/j.1440-1711.1994.tb03767.x

Nozawa, K., Fritzler, M. J., \& Chan, E. K. L. (2005). Unique and shared features of Golgi complex autoantigens. Autoimmunity Reviews, 4(1), 35-41. doi:10.1016/j.autrev.2004.06.002

Nozawa, K., Fritzler, M. J., von Mülen, C. A., \& Chan, E. K. L. (2004). Giantin is the major Golgi autoantigen in human anti-Golgi complex sera. Arthritis Research \& Therapy, 6(2), R95-102. doi:10.1186/ar1035

Rodríguez, J. L., Gelpi, C., Thomson, T. M., Real, F. J., \& Fernández, J. (1982). Anti-Golgi complex autoantibodies in a patient with Sjögren syndrome and lymphoma. Clinical and Experimental Immunology, 49(3), 579-86.

Vermeersch, P., Van Den Bergh, K., Blockmans, D., Westhovens, R., \& Bossuyt, X. (2011). Anti-Golgi autoantibodies are not clinically associated with systemic autoimmune diseases. $A n-$ nals of the Rheumatic Diseases, 70(1), 234-235. doi:10.1136/ard.2009.126391

Wallis, D., Greing, A., Dunphy, J., Owen, P., \& McHugh, N. (2012). Anti-Golgi autoantibodies: Prevalence and disease associations in a rheumatic disease population. International Journal of Rheumatic Diseases, 15(2), 2011-2013. doi:10.1111/j.1756185X.2011.01655.X 